\title{
Toxidez de alumínio em plântulas de grápia (Apuleia leiocarpa Vog. Macbride)
}

\author{
Aluminium toxicity on grápia (Apuleia leiocarpa Vog. Macbride) seedlings
}

\author{
Roni Paulo Fortunato ${ }^{1}$ Fernando Teixeira Nicoloso $^{2}$
}

\section{RESUMO}

A toxidez de alumínio $\left(A l^{3+}\right)$ afeta o crescimento vegetal através de sua ação nas regiões meristemáticas da raiz e pela diminuição da absorção de água e nutrientes. $O$ presente trabalho teve como objetivo avaliar os efeitos do $\mathrm{Al}^{3+}$ no crescimento de plântulas de grápia (Apuleia leiocarpa Vog. Macbride). Em condições de câmara climatizada, as plantas foram cultivadas por 11 dias em minirizotrons contendo substrato geleificado $\left(7 \mathrm{~g} \mathrm{~L}^{-1}\right.$ de ágar) e quatro concentrações de $\mathrm{Al}^{3+}\left(0,0 ; 2,5 ; 5,0\right.$ e 10,0mg $\left.\mathrm{L}^{-1}\right)$. Em intervalos de 24h, avaliaram-se as taxas de elongação absoluta e relativa da raiz principal $e$ o aparecimento das raízes secundárias. Além disso, aos 7 e 11 dias de cultivo, foram analisados o pH da rizosfera, a altura da planta, comprimento da raiz principal, comprimento total das raízes, número e comprimento de raízes secundárias, massa seca de raízes e da parte aérea, bem como a relação entre a massa seca de raízes e da parte aérea. Plantas jovens de grápia são tolerantes à presença de $A l^{3+}$ no substrato de cultivo até a concentração de $10,0 \mathrm{mg} \mathrm{L}^{-1}$. As taxas de elongação absoluta e relativa da raiz principal de plântulas de grápia na presença de $\mathrm{Al}^{3+}$ a 10,0mg $\mathrm{L}^{-1}$ indicam a existência de um período de adaptação ao $\mathrm{Al}^{3+}$ de aproximadamente $48 \mathrm{~h}$. A tolerância ao $\mathrm{Al}^{3+}$ depende da elevação do $\mathrm{pH}$ da rizosfera.

Palavras-chave: espécie florestal, crescimento, pH rizosfera, $A l^{3+}$, minirizotrom.

\section{ABSTRACT}

Aluminium $\left(\mathrm{Al}^{3+}\right)$ toxicity affects plant root meristem growth and decreases water and nutrient uptake. The aim of this work was to evaluate the effects of $\mathrm{Al}^{3+}$ on the growth of grapia (Apuleia leiocarpa Vog. Macbride) seedling. Under climatized chamber conditions, seedlings were grown for $11 \mathrm{~d}$ on minirhizotrons in the presence of 0.0, 2.5, 5.0, or $10.0 \mathrm{mg} \mathrm{L}^{-1} A l^{3+}$ in the growth medium, solidified with $7 \mathrm{~g} \mathrm{~L}^{-1}$ agar. At $24 \mathrm{~h}$ intervals, the absolute and relative elongation rate of the tap root, and the appearance of secondary roots were evaluated; at 7 and 11d of cultivation the rhizosphere $\mathrm{pH}$, plant height, length of the tap root, length of the root system, number and length of the secondary roots, dry weight of roots, dry weight of shoots and of the whole plant, and root/shoot dry weight ratio were analyzed. Seedlings of grapia are tolerant to $A l^{3+}$ presence in the growth substrate up to $10.0 \mathrm{mg} \mathrm{L}^{-1}$. Absolute and relative elongation rate of the tap root of seedlings indicate the existence of an adaptation period of about $48 \mathrm{~h}$ to high $\mathrm{Al}^{3+}\left(10.0 \mathrm{mg} \mathrm{L}^{-1}\right)$. The tolerance of seedlings to $\mathrm{Al}^{3+}$, at concentration of $10.0 \mathrm{mg} \mathrm{L} \mathrm{L}^{-1}$, depends on the increasing of rhizosphere $\mathrm{pH}$.

Key words: forest specie, growth, rhizosphere $\mathrm{pH}, \mathrm{Al}^{3+}$, minirhizotrom.

\section{INTRODUÇÃO}

A grápia (Apuleia leiocarpa Vog. Macbride) é uma espécie florestal que apresenta ampla distribuição geográfica no território brasileiro, porém atualmente se acha bastante descontínua, devido à devastação intensa das matas e à falta de reposição através do reflorestamento (MATTOS \& GUARANHA, 1983). Apresenta madeira de lei de primeira qualidade, portanto, de grande importância para o setor madeireiro. Outros usos relevantes são fonte de energia, medicinal, ornamental, reflorestamento ambiental, bem como produção de substâncias tanantes (CARVALHO, 1994). NICOLOSO et al. (1999) constataram que o comprimento do sistema radicular da grápia não diferiu entre as plantas cultivadas nos horizontes A e B de um Podzólico vermelho amarelo, que possuíam, respectivamente, $43 \%$ e $53 \%$ de saturação de alumínio. Portanto, esses

${ }^{1}$ Engenheiro Agrônomo, MSc, Assessor Técnico da SLC Agrícola Ltda, Luziânia, GO.

${ }^{2}$ Engenheiro Agrônomo, PhD, Professor Adjunto do Departamento de Biologia, Universidade Federal de Santa Maria (UFSM), 97119-390, Santa Maria, RS. Autor para correspondência. E-mail: nicoloso@base.ufsm.br. 
resultados indicam tolerância da grápia à alta disponibilidade deste elemento químico.

Um dos principais fatores limitantes à produção vegetal em solos ácidos é o predomínio do alumínio na forma trocável (Al ${ }^{3+}$ ) (RITCHIE, 1995; VON UEXKÜLL \& MUTERT, 1995), sendo que a parte compreendida entre a região meristemática e de elongação das raízes é que parece ser a mais sensível a ação desse íon (SUVAGURU \& HORST, 1998). Na célula, o $\mathrm{Al}^{3+}$ altera as propriedades da parede e da plasmalema, pois afeta o sistema de carregadores de nutrientes, problemas que resultam na inibição da elongação celular do eixo principal, tornando as raízes mais grossas e pouco funcionais (RYAN et al., 1993; KOCHIAN, 1995).

A tolerância ao $\mathrm{Al}^{3+}$, como conseqüência da variabilidade genética, consiste no principal fator individual que confere adaptação das espécies cultivadas em solos ácidos. Em plantas de Triticum aestivum, Lupinus alba e Thea sinensis, foi observado que as raízes liberam ácidos orgânicos, principalmente ácido málico e ácido cítrico, que complexam o $\mathrm{Al}^{3+}$ na rizosfera, tornando-o insolúvel (ANDRADE et al., 1997; JONES, 1998). PARKER (1995) salienta a hipótese da existência de um período inicial, de mais ou menos de $12 \mathrm{~h}$, de inibição do crescimento das raízes pelo $\mathrm{Al}^{3+}$, sendo que durante esse tempo, as espécies tolerantes estariam adaptando-se à presença de $\mathrm{Al}^{3+}$, ressaltando ainda que essas fases são muito dependentes dos genótipos em estudo e do tempo de duração de exposição a esse íon.

A alteração do $\mathrm{pH}$ da rizosfera consiste em outro mecanismo que pode contribuir para a adaptação dos vegetais à presença de $\mathrm{Al}^{3+}$, tendo sido observada tendência das espécies tolerantes em aumentar o $\mathrm{pH}$ da rizosfera em relação às espécies sensíveis ao $\mathrm{Al}^{3+}$ (MUGWIRA\& PATEL, 1977; FOY \& FLEMING, 1982), tornando-o não tóxico às plantas. Contudo, esse efeito não pode ser avaliado de forma isolada, pois com a elevação do $\mathrm{pH}$ da rizosfera diminui-se também a concentração de $\mathrm{H}^{+}$na solução do solo e aumenta-se a concentração de cálcio e magnésio ligados ao apoplasto das células da raiz, que amenizam os efeitos do alumínio (BLAMEY et al., 1993; TAN et al., 1993; CLEGG \& GOBRAN, 1995).

A caracterização da taxa de elongação de raízes constitui fator importante no diagnóstico dos sintomas da toxidez de $\mathrm{Al}^{3+}$. Porém, isso é viável somente pelo uso de métodos não destrutivos. Vários métodos não destrutivos foram desenvolvidos. Entre eles, destaca-se o uso de rizotrons e suas variações (HEERAMAN \& JUMA, 1993; KLEPPER \& KASPAR, 1994; MCCULLY, 1999). Alguns trabalhos foram feitos em condições controladas de crescimento com rizotrons de pequeno tamanho, sendo já relatada a caracterização da taxa de elongação de raízes em Eucalyptus nitens e E. globulus (CAHN et al., 1989) e crescimento de raízes laterais em milho (MISRA, 1999).

$\mathrm{O}$ presente trabalho teve como objetivo caracterizar os efeitos do $\mathrm{Al}^{3+}$ no crescimento de plântulas de grápia.

\section{MATERIAL E MÉTODOS}

O presente trabalho foi conduzido no Laboratório de Biotecnologia Vegetal pertencente ao Departamento de Biologia da Universidade Federal de Santa Maria (UFSM). Realizou-se um experimento em condições de câmara climatizada, sob temperatura constante de $25 \pm 1{ }^{\circ} \mathrm{C}$, umidade relativa do ar entre 50 $60 \%$ e fotoperíodo de $16 \mathrm{~h} \mathrm{luz}$, com intensidade luminosa de 1500 lux fornecida por lâmpadas fluorescentes branca-frias.

Cerca de 100 sementes, após a superação da dormência, segundo método descrito por NICOLOSO et al. (1997), foram germinadas em placas de petri sobre papel filtro umedecido com água deionizada. Quando a radícula apresentou cerca de $5 \mathrm{~mm}$ de comprimento, procedeu-se a transferência das sementes para recipientes especiais de vidro, denominados de minirizotrom (Figura 1a), que consistiu de uma caixa de vidro possuindo três faces pintadas de preto e uma face transparente. O minirizotrom ficou apoiado sobre uma superfície de madeira pintada de preto, instalado numa estrutura metálica com inclinação de $35^{\circ}$. Utilizouse como substrato de cultivo o meio MS (MURASHIGE \& SKOOG, 1962) geleificado a $7 \mathrm{~g} \mathrm{~L}^{-1}$ de ágar.

Os tratamentos consistiram de quatro concentrações de alumínio: 0,0; 2,5; 5,0 e 10,0 $\mathrm{mg} \mathrm{L}^{-1} \mathrm{de}$ $\mathrm{Al}^{3+}\left(\mathrm{AlCl}_{3}\right)$, em delineamento experimental inteiramente casualizado, com seis repetições e uma planta por unidade experimental. As concentrações de nutrientes no substrato foram as seguintes: $120 \mathrm{mg} \mathrm{L}^{-1} \mathrm{de} \mathrm{N}$ $\left(\mathrm{KNO}_{3}, \mathrm{NH}_{4} \mathrm{H}_{2} \mathrm{PO}_{4}, \mathrm{Ca}\left(\mathrm{NO}_{3}\right)_{2}\right), 10 \mathrm{mg} \mathrm{L}^{-1}$ de P $\left(\mathrm{NH}_{4} \mathrm{H}_{2} \mathrm{PO}_{4}\right), 80 \mathrm{mg} \mathrm{L}^{-1}$ de $\mathrm{K}\left(\mathrm{KNO}_{3}\right), 20 \mathrm{mg} \mathrm{L}^{-1}$ de $\mathrm{Ca}$ $\left(\mathrm{Ca}\left(\mathrm{NO}_{3}\right)_{2}\right), 12 \mathrm{mg} \mathrm{L}^{-1}$ de $\mathrm{Mg}\left(\mathrm{MgSO}_{4}\right), 8 \mathrm{mg} \mathrm{L}^{-1}$ de S $\left(\mathrm{MnSO}_{4}, \mathrm{MgSO}_{4}, \mathrm{ZnSO}_{4}, \mathrm{CuSO}_{4}\right), 0,3 \mathrm{mg} \mathrm{L}^{-1}$ de $\mathrm{Mn}$ $\left(\mathrm{MnSO}_{4}\right), 0,3 \mathrm{mg} \mathrm{L}^{-1}$ de $\mathrm{Zn}\left(\mathrm{ZnSO}_{4}\right), 0,09 \mathrm{mg} \mathrm{L}^{-1}$ de $\mathrm{Mo}$ $\left(\mathrm{MoO}_{3}\right), 0,006 \mathrm{mg} \mathrm{L}^{-1} \mathrm{de} \mathrm{Cu}\left(\mathrm{CuSO}_{4}\right)$ e $1,5 \mathrm{mg} \mathrm{L}^{-1} \mathrm{de} \mathrm{Fe}$ (Fe-EDTA). O pH do substrato foi ajustado para 4,0 com uma solução de $\mathrm{HCl} 0,1 \mathrm{~mol} \mathrm{~L}^{-1}$ ou $\mathrm{NaOH} 0,1 \mathrm{~mol} \mathrm{~L}$ ${ }^{1}$, visando minimizar a precipitação do $\mathrm{Al}^{3+}$. A parte exposta do substrato ao ambiente, no minirizotrom, foi selada com parafilme para evitar a perda de umidade para o ambiente, exceto na região do caule das plântulas. 


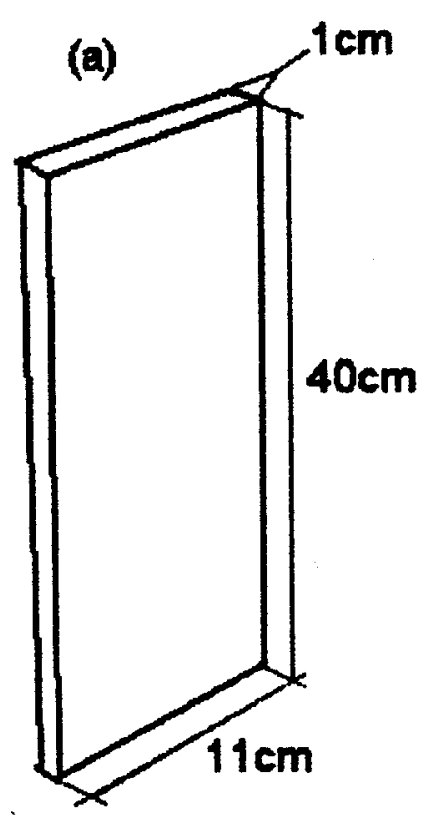

(b)

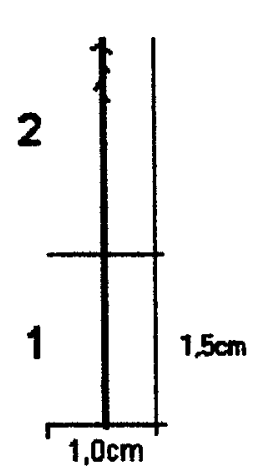

(c)

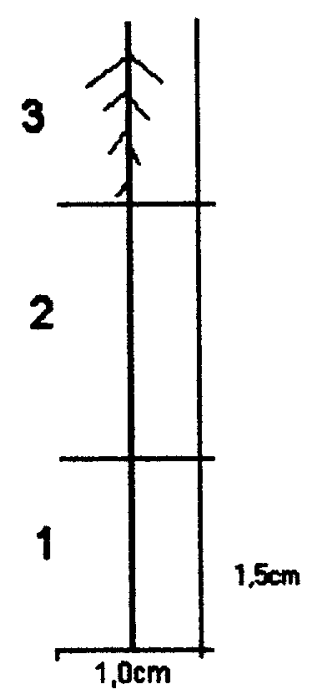

Figura 1 - Descrição esquemática do minirizotrom (a) e a indicação das regiões da rizosfera onde coletou-se o substrato para leitura de pH ao $7^{\circ}$ (b) e $11^{\circ}$ (c) dias após o plantio.

Após o transplante das plântulas para o substrato, durante um período de 11 dias, avaliou-se o comprimento da raiz principal em intervalos de 24 horas (até 144 horas), cujos valores foram utilizados para a determinação da taxa de elongação absoluta e taxa de elongação relativa, de acordo com a metodologia descrita por PARKER (1995):

$$
\begin{aligned}
& T E A=\frac{(C f-C i)}{T}=m m h^{-1} \\
& T E R=\frac{(T E A+A I)}{(T E A-A I)} \times 100=\%
\end{aligned}
$$

onde: TEA = taxa de elongação absoluta $\left(\mathrm{mm} \mathrm{h}^{-1}\right) ; \mathrm{Cf}=$ comprimento final $(\mathrm{mm}) ; \mathrm{Ci}=$ comprimento inicial $(\mathrm{mm}) ; \mathrm{T}=$ tempo $(\mathrm{h}) ; \mathrm{TER}=$ Taxa de elongação relativa (\%); $\mathrm{TEA}+\mathrm{Al}=$ taxa de elongação absoluta de tratamentos com a presença de alumínio e TEA-Al = taxa de elongação do tratamento testemunha.

$\mathrm{O} \mathrm{pH}$ da rizosfera foi analisado ao $7 \stackrel{\mathrm{o}}{\mathrm{e}} 11^{\mathrm{o}}$ dia, coletando-se todo substrato contido $(0,5 \mathrm{~cm}$ distante da raiz) na região apical, mediana e basal das raízes (Figura 1b,c) e de uma região sem raízes. A leitura do $\mathrm{pH}$ foi feita mantendo-se a relação substrato:água $(1: 1 \mathrm{v} / \mathrm{v})$. Nessas mesmas épocas, também foram avaliadas a altura da planta, comprimento da raiz principal, comprimento total das raízes (conforme método descrito por TENNANT, 1975), o surgimento, número e comprimento de raízes secundárias, massa seca de raízes e parte aérea, bem como a relação entre a massa seca de raízes e da parte aérea.

Utilizou-se o pacote estatístico SOC (Software Científico: NTIA/EMBRAPA) para a realização da análise dos dados.

\section{RESULTADOS E DISCUSSÃO}

Tanto no 7o como no 11ํ dia após o transplantio, as diferentes concentrações de $\mathrm{Al}^{3+}$ não proporcionaram alterações significativas com relação à altura de planta, comprimento da raiz principal, comprimento total das raízes, número de raízes secundárias, comprimento médio de raízes secundárias, massa seca de raízes, massa seca da parte aérea e a relação entre a massa de raízes e da parte aérea (Tabela 1). Visualmente todas as plântulas tiveram raízes normais, apresentando-se claras e sem alterações morfológicas, desse modo, indicando a ausência de toxidez de $\mathrm{Al}^{3+}$.

$\mathrm{Na}$ concentração de $10,0 \mathrm{mg} \mathrm{L}^{-1}$ de $\mathrm{Al}^{3+}$, as taxas de elongação absoluta e relativa da raiz principal apresentaram inibição acentuada até $48 \mathrm{~h}$ após o 
transplantio, recuperando-se, após esse período, até igualar-se aos demais tratamentos às $72 \mathrm{~h}$ (Tabela 2 ). O período compreendido nas $48 \mathrm{~h}$ iniciais parece ser o tempo necessário para adaptação do sistema radicular à presença de alumínio, período superior ao indicado por PARKER (1995), que sugere um período em torno de $12 \mathrm{~h}$ como o necessário para a adaptação ao $\mathrm{Al}^{3+}$. Contudo, esse curto período foi determinado a partir de inúmeros trabalhos com espécies anuais de crescimento rápido. Portanto, como a grápia apresenta crescimento lento, o período necessário para expressar sua adaptação ao $\mathrm{Al}^{3+}$ deve ser maior. Após 120h, de modo geral, ocorreu diminuição tanto na taxa de elongação absoluta como na taxa de elongação relativa. Esse fato deve-se, provavelmente, ao surgimento das raízes secundárias, diminuindo, assim, a taxa de crescimento do eixo principal da raiz (Tabela 2).
$\mathrm{Na}$ rizosfera da região apical da raiz principal, tanto no $7^{\circ}$ como no $11^{\circ}$ dia, verificou-se valores de $\mathrm{pH}$ significativamente superiores (entre 0,31 e 0,87 unidades de $\mathrm{pH}$ ) do que nas regiões basais, sendo esse efeito mais pronunciado na ausência de $\mathrm{Al}^{3+}$ (Tabela 3). O pH mais elevado na região apical da raiz deve-se à produção de mucilagens pela coifa da raiz, que atuam facilitando a penetração da raiz (MARSCHNER, 1995), bem como diminuem a toxicidade do $\mathrm{Al}^{3+}$ por formarem com este íon complexos através de Ca-pectatos (OSTATEK-BOCZYNSKI et al., 1995). A formação de um gradiente de $\mathrm{pH}$ na rizosfera da região apical em direção à base da raiz também foi constatada por BASHAN \& LEVANONY (1989). Estes autores observaram o mesmo comportamento de $\mathrm{pH}$ ao longo de raízes de milho.

Tanto no $7^{\circ}$ como no $11^{\circ}$ dia após o transplantio, em geral a região basal da raiz apresentou

Tabela 1 - Valores médios da altura de planta, comprimento da raiz principal, comprimento total das raízes, número de raízes secundárias, comprimento médio de raízes secundárias, massa seca de raízes, massa seca da parte aérea e relação entre a massa seca de raízes e da parte aérea de plântulas de grápia (Apuleia leiocarpa), cultivadas em minirizotrons aos 7 e 11 dias, na presença de diferentes concentrações de $\mathrm{Al}^{3+}\left(0,0 ; 2,5 ; 5,0\right.$ e $\left.10,0 \mathrm{mg} \mathrm{L}^{-1}\right)$.

\begin{tabular}{lcc}
\hline & & Tempo (dias) \\
\cline { 2 - 3 } & 7 & 11 \\
\hline Altura de planta (cm) & 4,1 & 4,8 \\
Comprimento da raiz principal (cm) & 7,2 & 9,7 \\
Comprimento total das raízes (cm) & 9,4 & 56,5 \\
Número de raízes secundárias & 28,2 & 64,2 \\
Comprimento médio de raízes secundárias (mm) & 1,2 & 7,3 \\
Massa seca de raízes (mg) & 5,3 & 6,4 \\
Massa seca da parte aérea (mg) & 31,5 & 33,5 \\
Relação entre a massa seca de raízes e da parte aérea & 0,2 & 0,16 \\
\hline
\end{tabular}

Tabela 2 - Taxa de elongação absoluta e relativa da raiz principal de plântulas de grápia (Apuleia leiocarpa) submetidas a diferentes concentrações de $\mathrm{Al}^{3+}$ no substrato de cultivo.

\begin{tabular}{|c|c|c|c|c|c|c|}
\hline \multirow{2}{*}{$\begin{array}{l}\text { Dose } \\
\text { alumínio }\end{array}$} & \multicolumn{6}{|c|}{ Intervalo de tempo (h) } \\
\hline & $0-24$ & $24-48$ & $48-72$ & $72-96$ & $96-120$ & $120-144$ \\
\hline$\left(\mathrm{mg} \mathrm{L}^{-1}\right)$ & \multicolumn{6}{|c|}{ Taxa de elongação absoluta $\left(\mathrm{mm} \mathrm{h}^{-1}\right)$} \\
\hline 0,0 & $0,277 b^{*}$ & $0,375 \mathrm{a}$ & $0,385 \mathrm{a}$ & $0,333 \mathrm{a}$ & $0,326 \mathrm{a}$ & $0,326 \mathrm{a}$ \\
\hline 2,5 & $0,354 \mathrm{a}$ & $0,347 \mathrm{a}$ & $0,350 \mathrm{ab}$ & $0,300 \mathrm{a}$ & $0,322 \mathrm{a}$ & $0,201 \mathrm{~b}$ \\
\hline 5,0 & $0,279 \mathrm{a}$ & $0,354 \mathrm{a}$ & $0,309 \mathrm{~b}$ & $0,306 \mathrm{a}$ & $0,282 \mathrm{a}$ & $0,261 \mathrm{ab}$ \\
\hline 10,0 & $0,214 \mathrm{c}$ & $0,229 \mathrm{~b}$ & $0,336 \mathrm{ab}$ & $0,337 \mathrm{a}$ & $0,322 \mathrm{a}$ & $0,270 \mathrm{ab}$ \\
\hline$\left(\mathrm{mg} \mathrm{L}^{-1}\right)$ & \multicolumn{6}{|c|}{ Taxa de elongação relativa (\%) } \\
\hline 0,0 & $100 \mathrm{~b}$ & $100 \mathrm{a}$ & $100 \mathrm{a}$ & $100 \mathrm{a}$ & $100 \mathrm{a}$ & $100 \mathrm{a}$ \\
\hline 2,5 & $118 \mathrm{a}$ & $92 \mathrm{a}$ & $99 a b$ & $76 \mathrm{~b}$ & $91 \mathrm{ab}$ & $59 \mathrm{c}$ \\
\hline 5,0 & $100 \mathrm{~b}$ & $94 \mathrm{a}$ & $80 \mathrm{~b}$ & $78 \mathrm{~b}$ & $79 \mathrm{~b}$ & $76 \mathrm{~b}$ \\
\hline 10,0 & $77 \mathrm{c}$ & $61 \mathrm{~b}$ & $87 \mathrm{ab}$ & $86 \mathrm{ab}$ & $91 \mathrm{ab}$ & $79 \mathrm{~b}$ \\
\hline
\end{tabular}

* Médias seguidas pela mesma letra na vertical não diferem entre si pelo teste de Tukey a 5\%.

Ciência Rural, v. 34, n. 1, jan-fev, 2004. 
pH semelhante ao do substrato na ausência de raízes. Entretanto, aos 11 dias a presença de raízes secundárias em formação na região basal provocou decréscimo no $\mathrm{pH}$ da rizosfera (Tabela 3), efeito que se acentuou na presença de 5,0 e $10,0 \mathrm{mg} \mathrm{L}^{-1}$ de $\mathrm{Al}^{3+}$. Esta redução de $\mathrm{pH}$ junto às raízes secundárias pode ser o resultado da excreção de $\mathrm{H}^{+}$pelas $\mathrm{H}^{+}$-ATPases, em função da geração do gradiente eletroquímico necessário à absorção mais acentuada de nutrientes nesta região (MARSCHNER, 1995), e/ou uma possível liberação de ácidos orgânicos pelas raízes (ANDRADE et al., 1997; JONES, 1998).

Comparando-se o efeito da rizosfera na região basal, tanto aos 7 como aos 11 dias de cultivo, observa-se que, nas doses de 2,5 e 5,0 $\mathrm{mg} \mathrm{L}^{-1} \mathrm{de}^{\mathrm{Al}^{3+}}$, o $\mathrm{pH}$ foi igual ou superior ao do tratamento testemunha. Associando-se este resultado ao fato de que a simples adição de $\mathrm{Al}^{3+}$ ao substrato reduziu o $\mathrm{pH}$ (meio de cultivo sem raízes) em cerca de 0,28 unidades, aos 11 dias de cultivo (Tabela 3), e que houve redução do $\mathrm{pH}$ em apenas 0,22 unidades na rizosfera da região basal pela adição de $10,0 \mathrm{mg} \mathrm{L}^{-1} \mathrm{de} \mathrm{Al}^{3+}$ (Tabela 3), pode-se indicar que a hipótese de elevação do $\mathrm{pH}$ na rizosfera, sugerida por MUGWIRA \& PATEL (1977) e FOY \& FLEMING (1982) como estratégia para amenizar a toxidez de $\mathrm{Al}^{3+}$, foi observada para a grápia na presença de $\mathrm{Al}^{3+}$.

Nas condições testadas no presente experimento, tentou-se conservar constante a atividade do $\mathrm{Al}^{3+}$ no substrato. Na confecção do substrato de cultivo, teve-se o cuidado de manter a concentração de fósforo e cálcio abaixo da empregada em soluções nutritivas completas, evitando assim uma possível reação entre o alumínio, o fósforo e o cálcio no substrato, que diminuiriam a toxicidade de $\mathrm{Al}^{3+}$ (BLAMEY et al., 1993; CLEGG \& GOBRAN, 1995). Se este fator não foi proeminente na diminuição da atividade do $\mathrm{Al}^{3+}$, o não surgimento dos sintomas típicos da toxidez desse elemento em vários parâmetros do crescimento de plântulas de grápia, indicam que as concentrações empregadas não foram suficientemente altas para causar toxidez, conseqüentemente, plantas jovens de grápia toleram a presença de $\mathrm{Al}^{3+}$ até concentração de $10,0 \mathrm{mg} \mathrm{L}^{-1}$.

$\mathrm{O}$ estudo dos efeitos do $\mathrm{Al}^{3+}$ no crescimento vegetal tem sido mais intenso em culturas agrícolas anuais, nas quais a concentração normalmente empregada situa-se abaixo de $10,0 \mathrm{mg} \mathrm{L}$ ${ }^{1}$. Pouco enfoque tem sido dado para as espécies florestais nativas brasileiras quanto à sua possível adaptação à presença de alumínio. Contudo, em mudas de goiabeira (Psidium guajava L.), SALVADOR et al. (2000) observaram que concentrações de $\mathrm{Al}^{3+}$ abaixo de $10,0 \mathrm{mg} \mathrm{L}^{-1}$ aumentaram a altura da planta e a área foliar, respectivamente, aos 30 e 90 dias de cultivo em solução nutritiva. Por outro lado, nas concentrações mais elevadas, até $25,0 \mathrm{mg} \mathrm{L}^{-1}$, o crescimento foi drasticamente reduzido, bem como os teores de macronutrientes e de Fe, Mn e Zn. Para as espécies florestais do hemisfério norte, também tem sido verificado que os sintomas de toxidez somente ocorrem em concentrações acima $10,0 \mathrm{mg} \mathrm{L}^{-1} \mathrm{de}^{3+} l^{3+}$. KELTJENS \& VAN LOENEN (1989) verificaram que na presença de $30,0 \mathrm{mg}$ de $\mathrm{Al}^{3+}$ não houve redução de crescimento e de produção de massa seca em Betula pendula e Pinus silvestris. Já nas espécies Larix decidua e

Tabela 3 - Valores de $\mathrm{pH}$ de regiões da rizosfera de plântulas de grápia (Apuleia leiocarpa) cultivadas na presença de diferentes concentrações de alumínio.

\begin{tabular}{|c|c|c|c|c|}
\hline \multirow[b]{3}{*}{ Região da raiz } & \multicolumn{4}{|c|}{$7^{\circ}$ dia } \\
\hline & \multicolumn{4}{|c|}{ Alumínio mg L ${ }^{-1}$} \\
\hline & 0,0 & 2,5 & 5,0 & 10,0 \\
\hline 1 (apical) & 4,70 a $\mathrm{A}$ & 4,65 a A & 4,56 a $\mathrm{A}$ & 4,17 a B \\
\hline 2 (basal) & $4,16 \mathrm{~b} \mathrm{~A}$ & $4,32 \mathrm{~b} \mathrm{~A}$ & $4,09 \mathrm{~b} \mathrm{AB}$ & $3,86 \mathrm{~b} \mathrm{~B}$ \\
\hline \multirow[t]{3}{*}{ Meio sem raiz } & $4,24 \mathrm{~b} \mathrm{~A}$ & $4,29 \mathrm{~b} \mathrm{~A}$ & 4,14 b A & $4,05 \mathrm{ab} A$ \\
\hline & \multicolumn{4}{|c|}{$11^{\circ} \mathrm{dia}$} \\
\hline & \multicolumn{4}{|c|}{ Alumínio mg L $\mathrm{L}^{-1}$} \\
\hline Região da raiz & 0 & 2,5 & 5,0 & 10,0 \\
\hline 1 (apical) & 4,73 a $\mathrm{A}$ & $4,66 \mathrm{a} A B$ & 4,44 a BC & 4,31 a C \\
\hline 2 (mediana) & $4,30 \mathrm{~b} \mathrm{~A}$ & $4,22 \mathrm{~b} \mathrm{~A}$ & $4,28 \mathrm{~b} \mathrm{~A}$ & $3,81 \mathrm{c} \mathrm{B}$ \\
\hline 3 (basal) & $3,86 \mathrm{c} \mathrm{B}$ & $4,09 \mathrm{~b} \mathrm{~A}$ & $3,98 \mathrm{c} \mathrm{AB}$ & $3,64 \mathrm{~d} C$ \\
\hline Meio sem raiz & $4,33 \mathrm{~b} \mathrm{~A}$ & $4,26 \mathrm{~b} \mathrm{AB}$ & $4,14 \mathrm{~b}$ BC & $4,05 \mathrm{~b} \mathrm{C}$ \\
\hline
\end{tabular}

* Médias seguidas pela mesma letra minúsculas, na coluna, e maiúsculas, na linha não diferem entre si pelo teste de Tukey a 5\%. 
Quercus robur, houve até um estímulo na produção de massa seca na presença de $\mathrm{Al}^{3+}$ em solução nutritiva. Também SCHIER (1985) observou efeitos negativos no crescimento de Picea rubens e Abies balsamae, somente em concentrações de $\mathrm{Al}^{3+}$ superiores a $50,0 \mathrm{mg} \mathrm{L}^{-1}$.

$\mathrm{O}$ não surgimento de sintomas de toxidez em plantas da grápia na presença de $\mathrm{Al}^{3+}$ até $10,0 \mathrm{mg} \mathrm{L}^{-1}$ sugere a adaptação dessa espécie a esse íon, fato já parcialmente observado por NICOLOSO et al. (1999), sendo que o mecanismo responsável por esse comportamento depende, pelo menos em parte, da elevação do $\mathrm{pH}$ da rizosfera.

\section{CONCLUSÕES}

Plântulas de grápia toleram a presença de $\mathrm{Al}^{3+}$ no substrato de cultivo até a concentração de $10,0 \mathrm{mg} \mathrm{L}^{-1}$, processo que depende da elevação do $\mathrm{pH}$ da rizosfera.

As taxas de elongação absoluta e relativa da raiz principal de plântulas de grápia na presença de $\mathrm{Al}^{3+}$ a $10,0 \mathrm{mg} \mathrm{L}^{-1}$ indicam a existência de um período de adaptação ao $\mathrm{Al}^{3+}$ de aproximadamente $48 \mathrm{~h}$.

\section{AGRADECIMENTOS}

À FAPERGS, ao CNPq e à FIPE/UFSM pelo financiamento deste trabalho.

\section{REFERÊNCIAS BIBLIOGRÁFICAS}

ANDRADE, L.R.M.; IKEDA, M.; ISHIZUKA, J. Stimulation of organic acid excretion by roots of aluminium-tolerant and aluminium-sensitive wheat varieties under aluminium stress. Revista Brasileira de Fisiologia Vegetal, Brasília, v.9, p.27-34, 1997.

BASHAN, Y.; LEVANONY, H. Effect of root environment on proton efflux in wheat roots. Plant and Soil, Dordrecht, v.119, p.191-197, 1989.

BLAMEY, F.P.C. et al. Factors affecting aluminium sorption by calcium pectate. Plant and Soil, Dordrecht, v.149, p.8794, 1993.

CAHN, M.D.; ZOBEL, R.W.; BOULDIN, D.R. Relationship between root elongation rate and diameter and duration of growth of lateral roots of maize. Plant and Soil, Dordrecht, v.119, p.271-279, 1989.

CARVALHO, P.E.R. Espécies florestais brasileiras, recomendações silviculturais, potencialidades e uso da madeira. Brasília : EMBRAPA-CNPF/SPI, 1994. 640p.

CLEGG, S.; GOBRAN, G.R. Effects of aluminium on growth and root reactions of phosphorus stressed Betula pendula seedlings. Plant and Soil, Dordrecht, v.168-169, p.173$178,1995$.
FOY, C.D.; FLEMING, A.L. Aluminium tolerances of two wheat genotypes related to nitrate reductase activities. Journal of Plant Nutrition, New York, v.5, p.1313-1333, 1982.

HEERAMAN, D.A.; JUMA, N.G. A comparasion of minirhizotron, core and monolith methods for quantifying barley (Hordeum vulgare L.) and fababean (Vicia faba L.) root distribution. Plant and Soil, Dordrecht, v.148, p.2941, 1993.

JONES, D.L. Organic acids in the rhizosphere - a critical review. Plant and Soil, Dordrecht, v.205, p.25-44, 1998.

KELTJENS, W.G.; VAN LOENEN, E. Effects of aluminium on growth and chemical composition of hidroponically grown seedlings of five different forest tree species. Plant and Soil, Dordrecht, v.119, p.39-50, 1989.

KLEPPER, B.; KASPAR, T.C. Rhizotrons: Their development and use in agricultural research. Agronomy Journal, Madison, v.86, p.745-753, 1994.

KOCHIAN, L.V. Cellular mechanisms of aluminium toxicity and resistance in plants. Annual Review of Plant Physiology and Plant Molecular Biology, Palo Alto, v.46, p.237-260, 1995.

MARSCHNER, H. Mineral nutrition of higher plants. 2.ed. San Diego : Academic, 1995. 889p.

MATTOS, N.F.; GUARANHA, J. Contribuição ao estudo da grápia (Apuleia leiocarpa). Porto Alegre : Instituto de Pesquisas de Recursos Naturais Renováveis “AP”, 1983. 25p. (Boletim Técnico, 12).

MCCULLY, M.E. Root in soil: Unearthing the complexities of roots and their rhizosfere. Annual Review of Plant Physiology and Plant Molecular Biology, Palo Alto, v.50, p.695-718, 1999.

MISRA, R.K. Root and shoot elongation of rhizotron-grown seedlings of Eucalyptus nitens and Eucalyptus globulus in relation to temperature. Plant and Soil, Dordrecht, v.206, p.37-46, 1999.

MUGWIRA, L.M.; PATEL, S.U. Root zone pH changes and ion uptake imbalances by triticale, wheat and rye. Agronomy Journal, Madison, v.69, p.719-722, 1977.

MURASHIGE, T.; SKOOG, F. A revised medium for rapid growth and bioassays with tabaco tissue cultures. Physiologia Plantarum, Copenhagen, v.15, p.473-197, 1962.

NICOLOSO, F.T. et al. Efeito de métodos de escarificação na superação da dormência de sementes e dois substratos na germinação e no desenvolvimento da Grápia (Apuleia leiocarpa). Ciência Rural, Santa Maria, v.27, p.419-424, 1997.

NICOLOSO, F.T. et al. Exigências nutricionais da grápia (Apuleia leiocarpa Vog. Macbride) em solo podzólico vermelho amarelo. Ciência Rural, Santa Maria, v.29, n.2, p.225-231, 1999.

OSTATEK-BOCZYNSKI, Z.; KERVEN, G.L.; BAMEY, F.P.C. Aluminium reactions with polygalacturonate and related organic ligands. Plant and Soil, Dordrecht, v.171, p.41-45, 1995. 
PARKER, D.R. Root growth analysis: an underutilized approach to understanding aluminium rhizotoxicity. Plant and Soil, Dordrecht, v.171, p.151-157, 1995.

RITCHIE, G.S.P. Soluble aluminium in acid soils: principles and practicalities. Plant and Soil, Dordrecht, v.171, p.1727, 1995 .

RYAN, P.R.; DITOMASE, J.M.; KOCHIAN, L.V. Aluminium toxicity in roots: an investigation of spatial sensitivity and the role of the root cap. Journal of Experimental Botany, Oxford, v.44, p.437-446, 1993.

SALVADOR, J.O. et al. Influência do alumínio no crescimento e na acumulação de nutrientes em mudas de goiabeira. Revista Brasileira de Ciência do Solo, Campinas, v.24, p.787796, 2000

SCHIER, G.A. Response of red spruce and balsam fir seedlings to aluminium toxicity in nutrient solutions.
Canadian Journal of Forest Research, Ottawa, v.15, p.29-33, 1985

SUVAGURU, M.; HORST, W.J. The distal part of the transition zone is the most aluminium-sensitive apical root zone of maize. Plant Physiology, Rockville, v.116, p.155$163,1998$.

TAN, K.; KELTJENS, W.G.; FINDENEGG, G.R. Evaluating the contribution of magnesium deficiency in the aluminium toxicity syndrome in twelve sorghum genotypes. Plant and Soil, Dordrecht, v.149, p.255-261, 1993.

TENNANT, D. A test of a modified line intersect method of estimating root length. The Journal of Ecology, Oxford, v.63, p.995-1000, 1975.

VON UEXKÜLL, H.R.; MUTERT, E. Global extent, development and economic impact of acid soils. Plant and Soil, Dordrecht, v.171, p.1-15, 1995. 